\title{
Impact of Sport Activity and Physical Exercise on Obstetrical and Perineal Outcomes at Delivery: A Prospective Study
}

\author{
Stefano Uccella, MD, PhD ${ }^{1,2}$ Paolo Manzoni, MD ${ }^{3}$ Nicola Marconi, MD ${ }^{2}$ Carlotta Toscani, CNM, MS ${ }^{2}$ \\ Sara Biasoli, MD ${ }^{2}$ Stefano Cianci, MD ${ }^{4}$ Massimo Franchi, MD $^{5}$ Paola Sorice, MD ${ }^{2}$ \\ Francesca Bertoli, CNM, MS² Pier Carlo Zorzato, MD ${ }^{1}$ Davide Gallina, MD ${ }^{1}$ Fabio Ghezzi, MD ${ }^{2}$ \\ Maurizio Serati, MD²
}
1 Division of Obstetrics and Gynecology, Department of Maternal, Neonatal and Infant Medicine, Neonatal and Infant Medicine, Nuovo Ospedale degli Infermi, ASL Biella, Italy
2 Department of Obstetrics and Gynecology, University of Insubria, F. Del Ponte Hospital, Varese, Italy
${ }^{3}$ Division of Pediatrics and Neonatology, Department of Maternal and Infant Medicine, Nuovo Ospedale degli Infermi, ASL Biella, Italy
${ }^{4}$ Division of Gynecologic Oncology, Fondazione Policlinico Universitario A. Gemelli IRCCS, Rome, Italy
${ }^{5}$ Department of Obstetrics and Gynecology, University of Verona, Italy

Am J Perinatol 2019;36(suppl S2):S83-S90.

\begin{abstract}
Address for correspondence Stefano Uccella, MD, PhD, Division of Obstetrics and Gynecology, Department of Maternal, Neonatal and Infant Medicine, ASL Biella, Via dei Ponderanesi, 2-13058, Ponderano, Biella, Italy (e-mail: stefucc@libero.it).
\end{abstract}

\begin{abstract}
Keywords

- sport

- physical exercise

- perineal tears

- episiotomy

- delivery outcomes

Objective This study was aimed to investigate the effects of physical activity on perineal outcomes at delivery according to the different levels and types of maternal physical activity before and during pregnancy.

Study Design We prospectively evaluated the obstetrical and perineal outcomes of all consecutive women who delivered at the Del Ponte Hospital, in the period between July 2014 and September 2014. Women were divided into three groups according to the features of physical activity performed before pregnancy: group 1: "very sporty women," group 2: “moderately sporty women," and group 3: "inactive women.” A subanalysis of our data was performed based on the specific type of sport activity, on the degree of involvement of perineal muscles during physical activity, and on the continuation/discontinuation of this activity during pregnancy.

Results A total of 135, 84, and 85 women were included in group 1, group 2, and group 3, respectively. The demographic characteristics were comparable among all the groups. Sport activity during pregnancy was more frequent in groups 1 and 2 (59.3 and $53.6 \%$, respectively, vs. $29.4 \%$ in group $3 ; p=0.003$ ). No differences among groups were detected in terms of perineal outcomes. A lower rate of episiotomy/lacerations $\geq$ 2nd degree was found among women who practiced sports that specifically involved the perineal muscles and who continued this practice during pregnancy.

Conclusion Perineal outcomes are not influenced by the intensity of sport activity performed before/during pregnancy. Continuous sports during pregnancy that specifically train the perineal muscles are associated with a lower rate of episiotomy and perineal lacerations $\geq$ 2nd degree.
\end{abstract}

Copyright @ 2019 by Thieme Medical Publishers, Inc., 333 Seventh Avenue, New York, NY 10001, USA. Tel: +1(212) 584-4662.
DOI https://doi.org/ 10.1055/s-0039-1691816. ISSN 0735-1631. 
In December 2015, the American College of Obstetricians and Gynecologists, ${ }^{1}$ in accordance with the 2008 physical activity guidelines for Americans, ${ }^{2}$ has recommended the practice of physical/sport activity during pregnancy 3 to 5 times a week for at least 30 minutes at medium intensity and for 20/60 minutes at high intensity. These recommendations are the result of a comprehensive analysis of all the studies designed to clarify the role of physical activity in pregnant women. The potential impact of physical activity on pregnancy always raised many concerns and debates, due to the unjustified fear for miscarriage, poor fetal growth, possible injuries, and risk of premature delivery. ${ }^{3}$ Opposing these misleading but still popular beliefs in the absence of absolute contraindications, scientific evidence has shown that physical activity provides clear benefits over sedentary habits in terms of both fetal and maternal status. In particular, physical exercise allows a better prevention and control of gestational diabetes in obese women, preeclampsia, preterm birth, varicose veins, and deep vein thrombosis. ${ }^{4,5}$ Moreover, other possible advantages include control of weight gain, reduction of lower back pain complaints, decreased cesarean and operative vaginal deliveries, shorter postpartum recovery time, and positive effects on maternal psychological well-being. ${ }^{6}$

Sport in pregnancy was also found to have no detrimental effects in terms of fetal-neonatal outcomes; a reduction in the average neonatal weight at birth has been described, but no increased risk of fetal growth restriction was observed. ${ }^{7}$

Consequently, aerobic physical activity is encouraged by all the most important clinical guidelines dealing with pregnancy, although it is widely recognized that further research is necessary to define the impact of exercise on all the possible aspects of pregnancy.

One of the less studied aspects of this issue is represented by the possible impact of the intensity and type of physical activity on the perineal outcomes at the time of vaginal delivery, defined as the incidence of episiotomy and the rate and severity of perineal lacerations. The perineum is a complex musculofascial structure having a key role in the mechanism of delivery. ${ }^{8}$ Its relaxation is crucial at the time of fetal head expulsion and a higher tone of its muscles may have (at least theoretically) the potential to impair this process with possible negative effects in terms of risk of severe perineal lacerations. It is plausible to hypothesize that intense and prolonged exercise with specific solicitations on its structures may produce a thicker and stiffer perineum among sporty women.

Since the literature is devoid of evidence on this topic, it may be of utmost importance to investigate this issue, due to the well-known association between severe lacerations and threatening long-term side effects, such as urinary-fecal incontinence and dyspareunia.

In light of the previous considerations, the aim of the present prospective study has been to investigate the possible relationship between the type and intensity of physical activity performed before and during pregnancy, with the risk of vaginal lacerations at delivery.

\section{Materials and Methods}

This prospective study was conducted in the period between July 1, 2014 and September 15, 2014 at the Obstetrics and Gynecology Department of Del Ponte Hospital at Varese in Italy. All consecutive women who delivered at our Institution were considered eligible. Patients who were received cesarean section (whether elective or urgent) and those with multiple pregnancies were excluded from the analysis. Patients with a history of previous cesarean section were excluded, unless they had a successful trial of labor after the cesarean section (they were classified as nulliparous or multiparous on the base of any previous vaginal birth). No additional exclusion criteria were adopted.

Physical activity before and during pregnancy was investigated by the administration of a dedicated survey. Due to the absence of validated questionnaires in this field, we decided to create a specific form, with the aim to comprehensively investigate all the possible parameters associated with the outcomes of interest. The translated version of the questionnaire is reported in the - Appendix.

Patients were asked to report in detail the amount and the type of sport activity they regularly performed in the 3 years before the initiation of pregnancy. On the basis of the answers to the questionnaire, patients were divided into three groups, according to the intensity of physical and sports activity performed before the beginning of pregnancy: group 1 "very sporty women" (i.e., patients who practiced sport activity at agonistic level and/or those practicing physical activity for $\geq 3$ hours per week); group 2 "moderately sporty women" (i.e., patients performing physical activity for $\geq 2$ hours but $<3$ hours per week); group 3 "inactive patients" (including both patients performing very low sport activity $\leq 2$ hours per week and those who did not practice any sport or physical activity except for the normal activities of daily living).

We then analyzed the number of women in each group who continued their activities during pregnancy and how many women changed activity or dismissed it. We also considered how many women took the opportunity of being pregnant to start physical activity in Group 3.

Patients were also asked about the type of information (if any) they received regarding sport and physical activity during pregnancy and about who provided this kind of information.

The primary outcome of the study was the occurrence of perineal lacerations or the performance of episiotomy at delivery. Perineal tears were defined according to the classification provided by Sultan. ${ }^{9}$ Briefly, the classification is as follows: 1st degree lacerations, in which only vaginal epithelium and/or perineal skin are involved; 2nd degree, if perineal muscles are involved; 3rd degree $A$, if less than $50 \%$ of external anal sphincter is involved; 3rd degree $B$, if more than $50 \%$ external anal sphincter is involved; 3rd degree C, if the laceration extends to the internal anal sphincter; and 4th degree, involving disruption of external and internal anal sphincter and rectal mucosa. ${ }^{9}$

At our Department the indications to episiotomy at the time of delivery have been strictly standardized, after the end of a previous study showing a wide interoperator variability in the 
performance of this type of procedure. ${ }^{10}$ Since 2014 the rate of episiotomy has remained stable around $15 \%$ of all deliveries (19\% in nulliparae) and we quarterly perform audits to confirm that indications to its performance are followed by the attending providers.

As a further analysis, we selected only nulliparous women and subdivided them into two groups according to the degree of stress determined by physical activity on the perineum (sports that highly stimulate and train the pelvic floor muscles vs. sports that do not stimulate specifically the same anatomical region). The sports classified as stimulating the pelvic floor muscles were: dance, artistic gymnastics, rhythmic gymnastics, athletics, figure skating, tennis, volleyball, basketball, soccer, baseball, running, horseback riding, and snowboarding. All other sports were included among the "nonstimulating" ones. We then finally divided these women in other two subgroups, women who continued that activity also during pregnancy and women who dismissed it before the beginning of pregnancy, to investigate the impact of these conditions on perineal outcomes at delivery.

\section{Statistical Analysis}

The statistical analysis was performed with Graphpad Prism 5.0 for Windows (GraphPad software, San Diego, CA) and SPSS version 21.0 for Windows (SPSS). The D'Agostino Person's test was used to evaluate if the continuous variables had a Gaussian distribution. In case of variables with normal distribution a Student's t-test was used. The $U$-test of MannWhitney was instead utilized to compare continuous variables in case of non-Gaussian distribution. The proportions were compared with the Fisher's exact test. A $p$-value $<0.05$ was considered to be statistically significant. Considering that the perineal outcomes were the primary endpoint of the present study, we considered the possible predictive factors for intact perineum, and we verified their association with this outcome at univariate analysis. The variables with at least a borderline association $(p<0.10)$ with intact perineum were then included in a multiple logistic regression model to verify which of them was independently associated with the outcome of interest.

\section{Results}

During the study period, 304 patients met inclusion criteria. Among them, 135 women were included in group 1 (very sporty women), 84 in group 2 (medium sporty women), and 85 in group 3 (inactive women). The percentage of nulliparous women was similar among groups ( 57.8 vs. 67.9 vs. $57.6 \%$ in groups 1,2 , and 3 , respectively; $p=0.27$ ). The demographic characteristics of the population are reported in - Table $\mathbf{1}$.

Patients in group 3 were significantly younger, compared with the other two groups. No other differences were observed in the patients' demographic characteristics.

Answers to the questionnaire are reported in -Table 2.

The percentage of women who were physically active during pregnancy was higher in groups 1 and 2 (59.3 and $53.6 \%$, respectively), compared with group 3 (29.4\%; $p=0.003$ ). The mean time dedicated to sport activity during pregnancy was higher in group 1 and progressively decreased in the other two groups. Walking was the most commonly reported activity. Women in group 1 were more likely to practice more than one sport activity per week (-Fig. 1 ).

Advice regarding the practice of physical activity during pregnancy (-Table 2) was provided to less than 50\% of women in all groups $(48.8,47.6$, and $37.6 \%$ in groups 1,3 , and 3 , respectively).

Among the different reasons for reducing or stopping completely physical activity in pregnancy, the answer "personal reasons" (which included worries regarding maternal and fetal complications) was the most represented in all groups (-Fig. 2 ).

The outcomes of labor and delivery are reported in - Table 3.

The rate of induction of labor was higher in group 2 compared with group 1 ( 41.6 vs. $28.8 \%, p=0.04$ ). The other characteristics of labor and delivery were similar across all groups (- Table $\mathbf{3}$ ).

After stratification on parity, we found no difference in terms of duration of first and second stage of labor, estimated blood loss at delivery, as well as in the rate of epidural analgesia among the three groups ( - Table 3 ). Also neonatal outcomes were similar irrespectively of the level of physical activity before pregnancy ( - Table 4 ).

Perineal outcomes at delivery are presented in - Table 5.

A tendency toward a higher incidence of intact perineum was registered in group 1 compared with group $2(p=0.05)$. No significant differences were observed when comparing group 1 versus group 3 and group 2 versus group 3 . Specifically, the rate of episiotomy was similar among the groups, while there was a tendency toward a higher rate of perineal

Table 1 Demographic characteristics of the patients included in the three groups

\begin{tabular}{|c|c|c|c|c|}
\hline Characteristic & $\begin{array}{l}\text { Group } 1 \\
\text { (very sporty) } \\
n=135\end{array}$ & $\begin{array}{l}\text { Group } 2 \\
\text { (moderately sporty) } \\
n=84\end{array}$ & $\begin{array}{l}\text { Group } 3 \\
\text { (inactive) } \\
n=85\end{array}$ & $p$-Value \\
\hline Age (y) & $33.4 \pm 5.3$ & $33.1 \pm 4.6$ & $29.7 \pm 5.8$ & 0.004 \\
\hline Gestational week at delivery (range) & $40(33-41)$ & $40(35-41)$ & $39(28-41)$ & 0.06 \\
\hline Nulliparity (\%) & $78(57.8)$ & $57(67.9)$ & $49(57.6)$ & 0.27 \\
\hline Previous cesarean section (\%) & $6(4.4)$ & 0 & $3(3.5)$ & 0.18 \\
\hline Assisted reproductive techniques (\%) & $2(1.5)$ & $3(3.6)$ & 0 & 0.19 \\
\hline Premature rupture of membranes (\%) & $42(31.1)$ & $28(33.3)$ & $24(28.2)$ & 0.77 \\
\hline
\end{tabular}


Table 2 Data regarding the answers to the questionnaire

\begin{tabular}{|l|l|l|l|}
\hline & $\begin{array}{l}\text { Very sporty women } \\
(\boldsymbol{n}=135)\end{array}$ & $\begin{array}{l}\text { Moderately sporty women } \\
(\boldsymbol{n}=\mathbf{8 4})\end{array}$ & $\begin{array}{l}\text { Inactive women } \\
(\boldsymbol{n}=\mathbf{8 5})\end{array}$ \\
\hline Kept the same physical/sport activity (\%) & $13(9.6)$ & $9(10.7)$ & $2(2.4)$ \\
\hline Changed physical/sport activity (\%) & $67(49.7)$ & $36(42.9)$ & $6(7)$ \\
\hline Dismissed it completely (\%) & $55(40.7)$ & $39(46.4)$ & $12(14.1)$ \\
\hline Duration, min/wk (mean) & $231.8 \pm 182.1$ & $183.4 \pm 179.9$ & $135.6 \pm 47.5$ \\
\hline Physical/sport activity suggested by anyone (\%) & $66(48.8)$ & $40(47.6)$ & $32(37.6)$ \\
\hline Starting with a new physical/sport activity (\%) & NA & NA & $23(27.1)$ \\
\hline No starting (\%) & NA & NA & $42(49.4)$ \\
\hline Duration, min/wk, (mean) if starting activity & NA & NA & $161.7+112.2$ \\
\hline
\end{tabular}

Abbreviation: NA, not available.

\section{(very sporty women)}

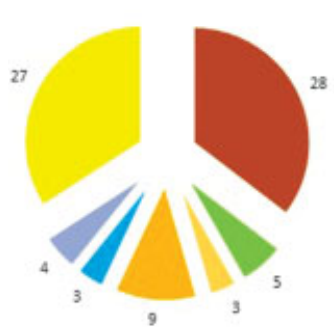

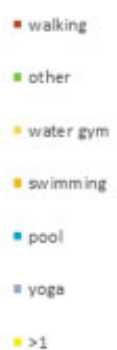

\section{(moderately sporty women)}

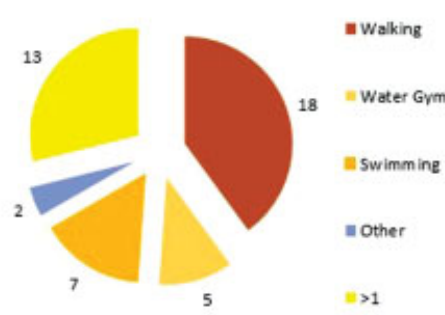

(Inactive women)

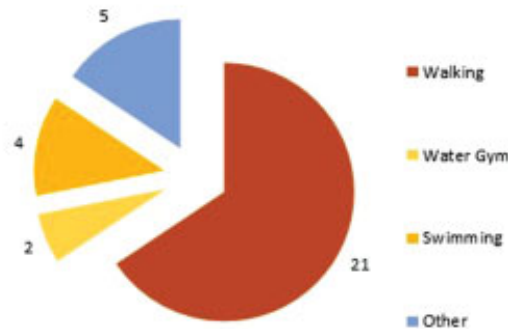

Fig. 1 Sport activities performed during pregnancy.

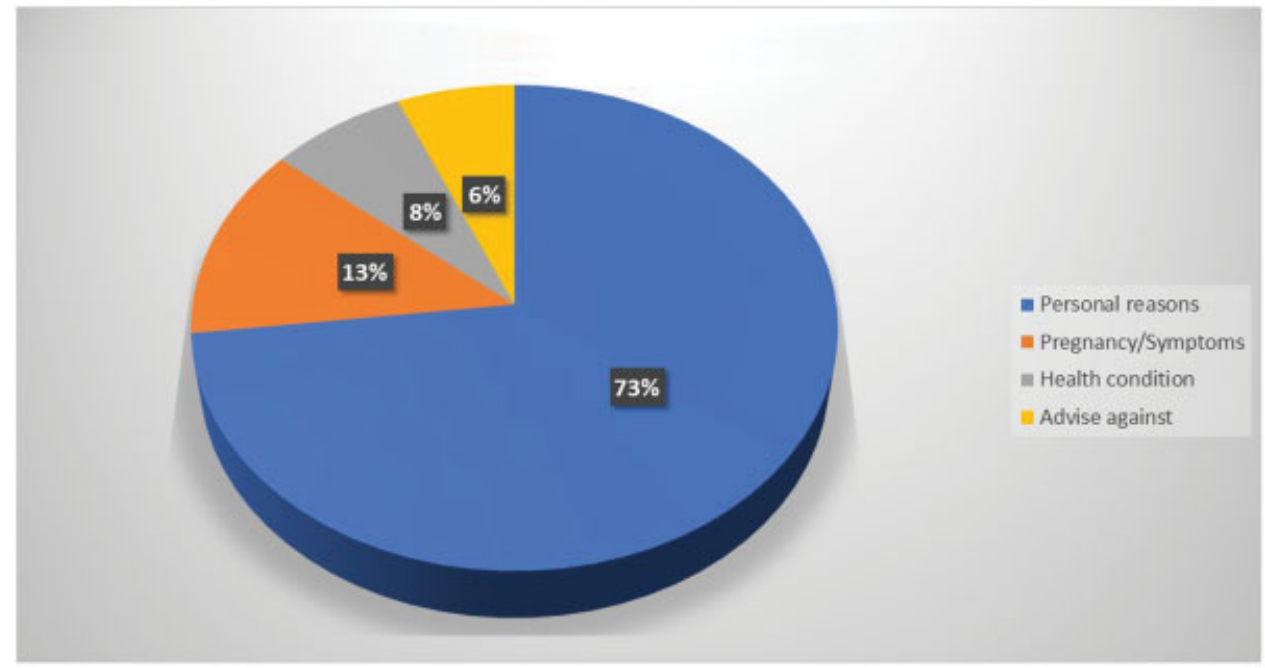

Fig. 2 Reasons for discontinuing sport activity in pregnancy.

lacerations $\geq 2$ nd degree in group 2 , compared with group 1 $(p=0.08)$.

We then analyzed data regarding only nulliparous women, according to the practice or not of sports which specifically solicit the pelvic floor muscles and on the basis of the discontinuation or continuation of this kind of activity during pregnancy. Data about these comparisons are provided in - Table 6.
No differences were observed between women who practiced sport activities soliciting the perineum versus those who did not practice this type of activity, if no distinction was made on the basis of continuation versus discontinuation during pregnancy. Conversely, we found a higher incidence of intact perineum among nulliparous women who continued practicing this kind of sports when compared with 
Table 3 Characteristics of labor and delivery

\begin{tabular}{|c|c|c|c|c|}
\hline & $\begin{array}{l}\text { Group } 1 \text { (very sporty) } \\
n=135\end{array}$ & $\begin{array}{l}\text { Group } 2 \text { (moderately sporty) } \\
n=84\end{array}$ & $\begin{array}{l}\text { Group } 3 \text { (inactive) } \\
n=85\end{array}$ & p-Value \\
\hline Spontaneous labor (\%) & $96(71.1)$ & $49(58.3)$ & $56(65.9)$ & 0.15 \\
\hline Induction of labor (\%) & $39(28.8)$ & $35(41.6)$ & $29(34.1)$ & 0.15 \\
\hline Augmentation of labor (\%) & $15 / 96(15.6)$ & $12 / 49(24.5)$ & $6 / 56(10.7)$ & 0.16 \\
\hline Instrumental vaginal delivery (\%) & $4(3)$ & $1(1.2)$ & $4(4.7)$ & 0.40 \\
\hline \multicolumn{5}{|l|}{ Duration of 1st stage of labor } \\
\hline Nulliparous (min) & $243 \pm 191$ & $252 \pm 199$ & $195 \pm 140$ & 0.60 \\
\hline Pluriparous (min) & $124 \pm 109$ & $77 \pm 59$ & $120 \pm 95$ & 0.60 \\
\hline \multicolumn{5}{|l|}{ Duration of 2 nd stage of labor } \\
\hline Nulliparous (min) & $60 \pm 45$ & $55 \pm 27$ & $67 \pm 44$ & 0.61 \\
\hline Pluriparous (min) & $24 \pm 17$ & $16 \pm 13$ & $22 \pm 19$ & 0.27 \\
\hline \multicolumn{5}{|l|}{ Estimated blood loss (> $500 \mathrm{~mL}$ ) } \\
\hline Nulliparous (\%) & $15 / 78(19.2)$ & $12 / 57(21.1)$ & $14 / 49(28.6)$ & 0.45 \\
\hline Pluriparous (\%) & $12 / 57(21.1)$ & $1 / 27(3.7)$ & $6 / 36(16.7)$ & 0.13 \\
\hline \multicolumn{5}{|l|}{ Epidural analgesia } \\
\hline Nulliparous (\%) & $47 / 78(60.3)$ & $38 / 57(66.6)$ & $26 / 49(53.1)$ & 0.36 \\
\hline Pluriparous (\%) & $13 / 57(22.8)$ & $7 / 27(25.9)$ & $9 / 36(25)$ & 0.94 \\
\hline
\end{tabular}

Note: Data are expressed as average \pm standard deviation or absolute number (\%).

Table 4 Neonatal outcomes

\begin{tabular}{|c|c|c|c|c|}
\hline & $\begin{array}{l}\text { Group } 1 \text { (very sporty) } \\
n=135\end{array}$ & $\begin{array}{l}\text { Group } 2 \text { (moderately sporty) } \\
n=84\end{array}$ & $\begin{array}{l}\text { Group } 3 \text { (inactive) } \\
n=85\end{array}$ & $p$-Value \\
\hline Birth weight $(g)$ & $3,280 \pm 460$ & $3,247 \pm 523$ & $3,172 \pm 472$ & 0.35 \\
\hline Apgar's score, $1 \mathrm{~min}$ & $9.2 \pm 1.1$ & $9.2 \pm 1.1$ & $9 \pm 12$ & 0.54 \\
\hline Apgar's score, $5 \mathrm{~min}$ & $9.8 \pm 0.5$ & $9.8 \pm 0.4$ & $9.7 \pm 0.6$ & 0.64 \\
\hline Umbilical artery $\mathrm{pH}$ & $7.2 \pm 0.1$ & $7.2 \pm 0.1$ & $7.2 \pm 0.1$ & 0.002 \\
\hline Birth weight $>4,000 \mathrm{~g}(\%)$ & $12(8.9)$ & $4(4.8)$ & $3(3.5)$ & 0.22 \\
\hline IUGR/SGA & 2 & 2 & 1 & 0.81 \\
\hline Preterm delivery < 37wk (\%) & $5(3.7)$ & $6(7.1)$ & $4(4.7)$ & 0.52 \\
\hline
\end{tabular}

Abbreviations: IUGR, intra-uterine growth restriction; SGA: small for gestational age.

Table 5 Perineal outcomes

\begin{tabular}{|c|c|c|c|c|}
\hline & $\begin{array}{l}\text { Group } 1 \text { (very sporty) } \\
n=135\end{array}$ & $\begin{array}{l}\text { Group } 2 \text { (moderately sporty) } \\
n=84\end{array}$ & $\begin{array}{l}\text { Group } 3 \text { (inactive) } \\
n=85\end{array}$ & $p$-Value \\
\hline Episiotomy (\%) & $32(23.7)$ & $20(23.8)$ & $22(25.9)$ & 0.91 \\
\hline $\begin{array}{l}\text { Episiotomy for perineal } \\
\text { stiffness (\%) }\end{array}$ & $15 / 32(46.9)$ & $7 / 20(35)$ & $11 / 22(50)$ & 0.58 \\
\hline Intact perineum (\%) & $40(29.6)$ & $15(17.9)^{a}$ & $25(29.4)^{b}$ & 0.12 \\
\hline 1st degree laceration (\%) & $45(33.3)$ & $29(34.5)$ & $24(28.3)$ & 0.64 \\
\hline 2nd degree laceration (\%) & $18(13.3)^{c}$ & $19(22.6)^{c}$ & $14(16.5)$ & 0.20 \\
\hline$>$ 2nd degree laceration (\%) & 0 & $1(1 . .2)$ & 0 & 0.27 \\
\hline
\end{tabular}

${ }^{\mathrm{a}} p=0.05$ group 1 versus group 2 .

${ }^{\mathrm{b}} p=0.08$ group 2 versus group 3 .

${ }^{c} p=0.08$ group 1 versus group 2 . 
Table 6 Perineal outcomes according to the practice or not of sports which specifically solicit the pelvic floor muscles and on the basis of the discontinuation or continuation of this kind of activity during pregnancy

\begin{tabular}{|l|l|l|l|l|l|}
\hline & $\begin{array}{l}\text { Sport not soliciting } \\
\text { the perineum } \\
(\boldsymbol{n}=\mathbf{5 1 )}\end{array}$ & $\begin{array}{l}\text { Sport soliciting } \\
\text { the perineum } \\
\text { discontinued }(\boldsymbol{n}=48)\end{array}$ & $\begin{array}{l}\text { Sport soliciting } \\
\text { the perineum } \\
\text { continued }(\boldsymbol{n}=36)\end{array}$ & $\begin{array}{l}\text { Inactive } \\
(\boldsymbol{n}=\mathbf{4 9})\end{array}$ & $p$-Value \\
\hline Episiotomy (\%) & $16(31.4)$ & $16(33.3)$ & $10(27.8)$ & $16(32.7)$ & 0.95 \\
\hline $\begin{array}{l}\text { Episiotomy for } \\
\text { perineal stiffness (\%) }\end{array}$ & $6 / 16(37.5)$ & $6 / 16(37.5)$ & $4 / 10(40)$ & $9 / 16(56.3)$ & 0.66 \\
\hline Intact perineum (\%) & $9(17.6)$ & $8(16.7)$ & $13(36.1)$ & $12(24.5)$ & 0.14 \\
\hline 1st degree laceration (\%) & $19(37.3)$ & $13(27.1)$ & $10(27.8)$ & $15(30.6)$ & 0.69 \\
\hline 2nd degree laceration (\%) & $7(13.7)$ & $10(20.8)$ & $3(8.3)$ & $6(12.2)$ & 0.40 \\
\hline$>$ 2nd degree laceration (\%) & 0 & $1(2.1)$ & 0 & 0 & 0.42 \\
\hline
\end{tabular}

Table 7 Univariate and multivariable analysis of factors potentially associated with intact perineum in nulliparous women

\begin{tabular}{|c|c|c|c|c|c|}
\hline & \multicolumn{2}{|l|}{ Univariate analysis } & \multirow[t]{2}{*}{$p$-Value } & \multirow{2}{*}{$\begin{array}{l}\text { Multivariable analysis } \\
\text { Odds ratio }(95 \% \mathrm{Cl})\end{array}$} & \multirow[t]{2}{*}{$p$-Value } \\
\hline & $\begin{array}{l}\text { Intact perineum } \\
(42)\end{array}$ & $\begin{array}{l}\text { Nonintact perineum } \\
\text { (142) }\end{array}$ & & & \\
\hline $\begin{array}{l}\text { Sport soliciting the } \\
\text { perineum continued } \\
\text { during pregnancy }(n=36)\end{array}$ & $13(30.9 \%)$ & $23(16.2 \%)$ & 0.03 & $2.43(1.09-5.26)$ & 0.03 \\
\hline Sporty women $(n=161)$ & $36(85.7 \%)$ & $125(88 \%)$ & 0.69 & - & - \\
\hline Epidural analgesia $(n=111)$ & $20(47.6 \%)$ & $91(64 \%)$ & 0.06 & $1.32(0.81-3.22)$ & 0.13 \\
\hline BMI kg/m² & $24.6(18.2-38.1)$ & $26.1(18.5-40)$ & 0.45 & - & - \\
\hline Age at delivery (wk) & $32(21-43)$ & $32(16-43)$ & 0.71 & - & - \\
\hline Gestational week at delivery & $40(28+3-41+6)$ & $40(32-41+6)$ & 0.99 & - & - \\
\hline Induction $(n=68)$ & $11(26.2 \%)$ & $57(40.1 \%)$ & 0.09 & $1.53(0.75-3.98)$ & 0.23 \\
\hline $\operatorname{MET}(n=92)$ & $20(14.1 \%)$ & $72(50.7 \%)$ & 0.73 & - & - \\
\hline
\end{tabular}

Abbreviations: $\mathrm{BMI}$, body mass index; $\mathrm{Cl}$, confidence interval; $\mathrm{MET}$, metabolic equivalent.

all the other women $(p=0.03)$, whereas epidural analgesia and induction of labor were associated with a tendency toward higher incidence of perineal lacerations or episiotomy. At multivariable analysis ( - Table 7 ), only the continuation of sports soliciting the perineum during pregnancy retained a significant association with perineal outcome at delivery and it was found to be an independent predictor of intact perineum (odds ratio [OR]: $0.41 ; 95 \%$ confidence interval $[\mathrm{CI}]: 0.19-0.92 ; p=0.03)$.

\section{Discussion}

Our original hypothesis that a tonic and trained perineum (with potentially thicker muscles) may predispose to a higher risk of perineal damage at the time of delivery was disproved by the results of the present study. In fact, we found no association between an intense practice of sport activity before pregnancy and the risk of perineal laceration or episiotomy. On the contrary, the continuation during pregnancy of sports that specifically solicit the perineal muscles was independently associated with a higher incidence of intact perineum. To explain our findings, we may speculate that physical exercise stressing the pelvic floor muscles may increase the elasticity of this anatomical region with better outcomes at the time of fetal head discharge. ${ }^{11}$

Perineal damage at delivery may be the cause of possible detrimental short- and long-term consequences to the mother, ${ }^{12,13}$ as well as the source of an increasing number of medical-legal litigations. Therefore, any additional knowledge about possible preventive strategies may be welcomed and regarded as having the potential of improving in some way the overall postpartum maternal well-being.

We emphasize that our results are applicable only to settings in which the rate of episiotomy is quite low (around $25 \%,{ }^{10}$ while they may not be generalizable to clinical contexts in which episiotomy is performed on a routine basis.

The present study represents a further demonstration that physical exercise and practice of sports activity during gestation is not harmful (even when the perineum is specifically solicited), and should be actively promoted. Yet, it is discouraging to observe how information regarding physical activity is uncommonly delivered to pregnant women; in our study, less than $50 \%$ of the patients declared that they had received specific counseling on this issue. It is difficult to 
establish whether this paucity of information is mainly due to absence of specific knowledge in the health care providers regarding the potential benefits, nonevidence based traditional belief that sport may be dangerous during pregnancy, or scarce interest by the patients about this issue. It should also be considered that diversities may be present regarding the perception of the possible consequences of physical activity during gestation across different geographical regions and different cultures. In any case, in line with the vast body of literature demonstrating the advantages of physical exercise during gestation, our study underlines once again that a stronger effort should be made to sustain a specific campaign of information about the beneficial consequences of sports activity in pregnant women.

The main merit of the present analysis is represented by the fact that previous research on sport and physical exercise during pregnancy was mainly focused on fetal and neonatal consequences or on the impact in terms of maternal comorbidities $^{5,14}$ but not on perineal outcomes at delivery. Other strengths include the prospective design, the inclusion of a considerable number of women (which allowed several meaningful subanalyses), and the detailed and consistent collection of data.

\section{Limitations}

Among the possible limitations of our study, we must mention that we were forced to use a nonvalidated questionnaire, due to the fact that we were not able to find any validated form in the literature specifically developed for the purposes of our analysis. Moreover, we had to rely only on self-reported data that could potentially under- or overestimate the real level of physical activity and the amount of pelvic floor solicitation. However, it should be recalled that self-reported assessment is the most commonly used tool for this type of studies and it has been found to be reliable in this and other settings. ${ }^{15,16}$ Finally, the arbitrary definition of our study groups (i.e., "very sporty," "moderately sporty," and "inactive" women) may be regarded as a further possible limitation of our analysis, particularly in the subdivision between "very sporty" and "moderately sporty" women. Nonetheless, also combining groups 1 and 2 together, or groups 2 and 3 together, we did not find any significant correlation of the intensity of sport activity with the outcome of interest (i.e., the rate of perineal tears/episiotomy at delivery), thus once again reinforcing our finding that the level of sport activity before pregnancy does not have detrimental effect on the perineal elasticity at the time of childbearing.

\section{Conclusion}

In conclusion, our study shows that perineal outcomes at delivery are not influenced by the degree of physical exercise before pregnancy. We found a significant increase in the rate of intact perineum among women who continue to practice sport activity soliciting the perineum during pregnancy. Regarding possible future research perspectives, it would be extremely interesting to investigate the possible consequences of the continuation during gestation of sports activities soliciting the perineum on the long-term risk of pelvic floor dysfunction. The goal should be to evaluate the possible (if any) effects of this practice on the rate of urinary and fecal incontinence and on sexual disorders several months after delivery.

\section{Condensation}

Sport activity and physical exercise do not appear to impair perineal outcomes at delivery.

Conflict of Interest

None declared.

\section{References}

1 ACOG Committee Opinion No. 650: Physical activity and exercise during pregnancy and the postpartum period. Obstet Gynecol 2015;126(06):e135-e142

2 American College of Sports Medicine. 2008 Physical Activity Guideline for Americans: ACSM's Guidelines for Exercise Testing and Prescription. 9th ed. Philadelphia, PA: Wolters Kluwer/Lippincott Williams \& Wilinkins; 2014

3 Barakat R, Perales M, Garatachea N, Ruiz JR, Lucia A. Exercise during pregnancy. A narrative review asking: what do we know? Br J Sports Med 2015;49(21):1377-1381

4 Evenson KR, Barakat R, Brown WJ, et al. Guidelines for physical activity during pregnancy: comparisons from around the world. Am J Lifestyle Med 2014;8(02):102-121

5 Sanabria-Martínez G, García-Hermoso A, Poyatos-León R, Álvarez-Bueno C, Sánchez-López M, Martínez-Vizcaíno V. Effectiveness of physical activity interventions on preventing gestational diabetes mellitus and excessive maternal weight gain: a meta-analysis. BJOG 2015;122(09):1167-1174

6 Nascimento SL, Surita FG, Godoy AC, Kasawara KT, Morais SS. Physical activity patterns and factors related to exercise during pregnancy: a cross sectional study. PLoS One 2015;10(06):e0128953

7 Leet T, Flick L. Effect of exercise on birthweight. Clin Obstet Gynecol 2003;46(02):423-431

8 Ornö AK, Marsál K, Herbst A. Ultrasonographic anatomy of perineal structures during pregnancy and immediately following obstetric injury. Ultrasound Obstet Gynecol 2008;32(04):527-534

9 Sultan AH. Obstetric perineal injury and anal incontinence. Clin Risk 1999;5(04):193-196

10 Cromi A, Bonzini M, Uccella S, et al. Provider contribution to an episiotomy risk model. J Matern Fetal Neonatal Med 2015;28(18): 2201-2206

11 Bø K, Hilde G, Jensen JS, Siafarikas F, Engh ME. Too tight to give birth? Assessment of pelvic floor muscle function in 277 nulliparous pregnant women. Int Urogynecol J Pelvic Floor Dysfunct 2013;24(12):2065-2070

12 Frohlich J, Kettle C. Perineal care. BMJ Clin Evid 2015;2015:1401

13 Serati M, Salvatore S, Khullar V, et al. Prospective study to assess risk factors for pelvic floor dysfunction after delivery. Acta Obstet Gynecol Scand 2008;87(03):313-318

14 Bisson M, Lavoie-Guénette J, Tremblay A, Marc I. Physical activity volumes during pregnancy: a systematic review and meta-analysis of observational studies assessing the association with infant's birth weight. AJP Rep 2016;6(02):e170-e197

15 Calvert S, Fleming V. Minimizing postpartum pain: a review of research pertaining to perineal care in childbearing women. J Adv Nurs 2000;32(02):407-415

16 Olivieri I, Bova S M, Fazzi E, et al; SOLE VLBWI Questionnaire Study Group. Patient-reported outcomes measure for children born preterm: validation of the SOLE VLBWI Questionnaire, a new quality of life self-assessment tool. Dev Med Child Neurol 2016;58 (09):957-964 


\section{Appendix}

ID

- Have you ever practiced physical activity/sport? YES NO

- If yes, which kind?

- How frequently? $\left(^{*}\right)$
a) Agonistic practice;
b) $>=3 \mathrm{~h} /$ week;
c) $>2 \mathrm{~h} /$ week;
d) $2 \mathrm{~h} /$ week;
e) $<2$ h/week;
f) $<2 \mathrm{~h} /$ month

- For how many years?

- Did you continue the practice during pregnancy? YES NO

- If no, when did you quit?
a) More than 3 years before pregnancy;
b) 1 year before;
c) At positive pregnancy test;
d) I trimester;
e) II trimester;
f) III trimester.

- Why?

- Did you change your physical activity/sport? YES No

- If yes, which physical activity/sport did you practice during pregnancy?

- Did someone advice you about practicing physical activity during pregnancy? YES NO

- If yes, who did advice you?
a) Physician
b) Midwife
c) Personal Trainer
d) Other (please specify)

- If you practiced physical activity/sport during pregnancy, would you be able to quantify your practice in "minutes per week"? $\min / \mathrm{sett}$ 